\title{
Synergetic effects of silver and gold nanoparticles in the presence of radiofrequency radiation on human kidney cells
}

\author{
Jafar Fattahi-asl, Mojtaba Karbalaee ${ }^{1}$, Masoud Sanatizadeh ${ }^{2}$, Payam Amini ${ }^{3}$ \\ Department of Medical Physics, School of Medicine, Ahvaz Jundishapur University of Medical Sciences, Ahvaz, 'Department of Medical \\ Physics and Medical Engineering, Student's Research Committee, School of Medicine, Isfahan University of Medical Sciences, Isfahan, \\ ${ }^{2}$ Department of Computer Engineering and Informatics Technology, Amirkabir University of Technology, ${ }^{3}$ Department of Epidemiology and \\ Reproductive Health, Reproductive Epidemiology Research Center, Royan Institute for Reproductive Biomedicine, ACECR, Tehran, Iran
}

\begin{abstract}
Objective: The aim of this study was to compare the effects of radiofrequency radiation (RF) in synergism with gold $(\mathrm{Au})$ and silver ( $\mathrm{Ag}$ ) nanoparticles (NPs) on the survival fraction of human normal kidney (HNK) and human embryonic kidney (HEK) cells. Materials and Methods: HNK and HEK cells were divided into three groups as control, 1 and $2 \mathrm{~h}$ /day-irradiated groups for 8 days. To compare the effects of RF in the presence of Au-NPs and Ag-NPs, the cells were incubated with NPs during the irradiation. In other words, six other groups were designed for the cell incubated with Au-NPs and Ag-NPs including control, 1 and $2 \mathrm{~h} /$ day-irradiated groups for 8 days. Generalized estimating equation model was applied to consider the natural correlation of repeated measurements over the time. Results: The mean survival fractions of HNK + Ag-NPs and HEK + Au-NPs were 0.098 less, 0.184 and 0.055 more than HEK cells, respectively. Along with the time, the mean fraction in HEK + Ag-NPs and HEK + Au-NPs groups in comparison with the HEK increased by the rate of 0.005 and decreased by the rates of 0.01 and 0.005 , respectively. The mean survival fractions in HEK + Ag-NPs and HEK + Au-NPs were significantly less than that of HEK cells $(P<0.05)$. Conclusions: RF radiation can affect both HNK and HEK cells when irradiated for $2 \mathrm{~h}$ /day for 8 days. The results showed that the Ag-NPs do not increase the synergistic effects of RF compared to the Au-NPs. RF radiation at the presence of Au-NPs can be used as an efficient treatment for melanoma.
\end{abstract}

Key words: Biological effect, gold nanoparticle, hyperthermia, in vitro study, radiofrequency radiation, silver nanoparticle

\section{INTRODUCTION}

In the recent decade, with the increased use of devices which produce radiofrequency radiation $(\mathrm{RF})$, controversial reports over the effects of such devices on human health have been presented. ${ }^{[1-4]}$ Although the effects of these radiations on human cells are not completely understood, it has been stated that RF radiation at $300 \mathrm{MHz}$ to several $\mathrm{GHz}$ can induce torques on

\section{Address for correspondence:}

Dr. Jafar Fattahi-asl,

Department of Medical Physics, School of Medicine, Ahvaz

Jundishapur University of Medical Sciences, Ahvaz, Iran.

E-mail: fatahi-j@ajums.ac.ir

\begin{tabular}{|l|l|}
\hline \multicolumn{2}{|c|}{ Access this article online } \\
\hline Quick Response Code: & Website: \\
\hline & www.jpionline.org \\
\hline
\end{tabular}

cell's molecules which results in a displacement of ions from unperturbed positions, vibrations inbound charges of both ions and electrons, and rotation and reorientation of dipolar molecules. ${ }^{[5]}$ Moreover, RF radiation may cause thermal effects on cells by thermal denaturation of critical targets. ${ }^{[5,6]}$

These effects might cause substantial damages in normal cells; even so, it can be employed in radiation oncology for cancer treatment. ${ }^{[7]}$ Some studies have demonstrated that tumor cells are more sensitive than healthy cells to RF microwave (MW)

This is an open access article distributed under the terms of the Creative Commons Attribution-NonCommercial-ShareAlike 3.0 License, which allows others to remix, tweak, and build upon the work non-commercially, as long as the author is credited and the new creations are licensed under the identical terms.

For reprints contact: reprints@medknow.com

How to cite this article: Fattahi-asI J, Karbalaee M, Sanatizadeh M, Amini P. Synergetic effects of silver and gold nanoparticles in the presence of radiofrequency radiation on human kidney cells. Int $\mathrm{J}$ Pharma Investig 2016;6:231-7. 
radiation. ${ }^{[8-10]}$ Therefore, the MW radiation can be used in partial necrosis of cancer cells, though this may be dangerous for normal surrounding tissues. ${ }^{[11-13]}$ In this regard, clinical studies have shown the difficulty of RF energy deposition in malignant tissue, deep within the body, without damaging neighboring healthy tissues. ${ }^{[14]}$

Over the past decade, nanotechnology is widely used to transport chemotherapeutic and biologic agents into the malignant tissue while sparing normal organs. ${ }^{[15]}$ In addition, a significant number of experimental and theoretical researches have demonstrated high MW absorption cross section of living cells in the presence of nanoparticles (NPs). ${ }^{[16,17]}$

The efficiency of MW radiation for therapy can be significantly enhanced by using nano-sized absorbing agents, which are targeted into a tumor area to absorb the radiation for the treatment of cancer cells as a selective destruction method. ${ }^{[18,19]}$ Such an effect can be achieved by using conductive nano-sized agents such as gold $(\mathrm{Au})$ and silver $(\mathrm{Ag}) \mathrm{NPs} .{ }^{[18,19]}$

The basic mechanism for MW energy absorption is related to the coupling of the magnetic moment of the magnetic NPs (MNPs) and the external MW field. ${ }^{[20]}$ The efficiency of the energy absorption is mainly related to the size, size distribution, and magnetic anisotropy of the NPs and the amplitude and frequency of the external radiation field. ${ }^{[20]}$

The aim of the present study was to investigate whether the 900 $\mathrm{MHz} \mathrm{MW}$ radiation can affect the survival of human normal kidney (HNK) and human embryonic kidney (HEK) cells. The focus of this work was to evaluate the synergistic effects of Au-NPs and Ag-NPS with MW radiation on HNK and HEK cell viability.

\section{MATERIALS AND METHODS}

\section{Synthesis of the gold nanoparticles}

$\mathrm{Au}-\mathrm{NPs}$ were synthesized according to standard wet chemical methods using sodium borohydride. [21] "Fifty $\mathrm{ml}$ of an aqueous solution containing $4.3 \mathrm{mg}$ of solid sodium borohydride was added to $100 \mathrm{ml}$ of a $100 \mu \mathrm{mol} / \mathrm{L}$ aqueous solution of tetrachloroauric acid. The solution was kept under vigorous stirring overnight."[21] Then, the Au-NPs were filtered through $0.22 \mu \mathrm{m}$ paper filter. The size of NP was investigated and calculated by the use of an electron microscopy. The average size of Au-NPs was 20-30 nm.

\section{Synthesis of the silver nanoparticles}

To synthesize the Ag-NPs, $0.001-0.01 \mathrm{M}$ of Ag nitrate solution was diluted in a vessel containing two platinum electrodes. Particle size was depended on the electrical current and voltage which fed into the system and was determined after reducing the transparent $\mathrm{Ag}$ nitrate solution following its conversion into a brown colloid system. ${ }^{[22]}$ The size of NP was investigated and calculated by the use of electron microscopy. The average size of Ag-NPs was 25-40 nm.

\section{Cell culture}

Experiments were carried out on HNK, provided from Isfahan University of Medical Science Laboratory (Isfahan, Iran) and HEK cells provided from Iran Cell Bank of Pasteur Institute (Tehran, Iran). The cells were cultured in $25 \mathrm{ml}$ culture flasks in Dulbecco's modified Eagle's medium (DMEM Gibco Laboratories, Cergy Pontoise, France) supplemented with $10 \%$ fetal bovine serum (FBS Gibco Laboratories, Cergy Pontoise, France), $2 \mathrm{mM}$ glutamine, $100 \mathrm{U}$ penicillin per $\mathrm{ml}$, and $100 \mathrm{mg}$ streptomycin per ml (Gibco Laboratories, Cergy Pontoise, France). Cells were grown in a humidified cell incubator at $37^{\circ} \mathrm{C}$ under $5 \% \mathrm{CO}_{2}$ atmosphere and $95 \%$ air.

\section{Experimental design}

To perform the experiment, 96-well plates were used. Cells were seeded, and the density of 5000 cells/well was put in each well. They were allowed to adhere and grown overnight in $200 \mu \mathrm{l}$ mediums.

At first, to determine the optimum NP concentration, the cells were incubated with fresh medium containing serial concentrations $(0-80 \mu \mathrm{M})$ of NPs for $2 \mathrm{~h} .^{[21]}$ Then, the survival of the cells was investigated after $24 \mathrm{~h}$ and was compared with the control group.

To investigate the effects of $\mathrm{RF}$ radiation on the cell proliferation, both the two cell lines of HNK and HEK were irradiated for 1 and 2 h/day for 8 days. For RF radiation, an RF simulator was used. The simulator was adjusted on $1.0 \mathrm{~W}$ and $900 \mathrm{MHz}$ frequency for the exposure. The distance between the simulator antenna and the wells was kept at $2.5 \mathrm{~cm}$.

To investigate the effect of RF radiation on the HNK cells, the cells were divided into three different groups. For the first group (Group 1-a), as control one, no radiation and NPs were applied. For the $2^{\text {nd }}$ and $3^{\text {rd }}$ groups (Groups 2-a and 3-a), the cells were exposed to RF simulator for 1 and $2 \mathrm{~h} /$ day, respectively, for 8 days.

The HEK cells were divided into nine groups. For the first group (Group 1-b), as control one, no radiation and NPs were applied. For the $2^{\text {nd }}$ and $3^{\text {rd }}$ groups (Groups 2-b and 3-b), the cells were exposed to an RF simulator for 1 and $2 \mathrm{~h} / \mathrm{day}$, respectively, for 8 days. For these two groups, NPs were not used. Moreover, to investigate the effects of NPs on the cell proliferation in the presence the RF radiation, six groups were designed. For the $4^{\text {th }}$ group (Group 4-b), no radiation was applied and the cells were incubated with Au-NPs for $2 \mathrm{~h} /$ day for 8 days. The $5^{\text {th }}$ and $6^{\text {th }}$ groups (Groups 5-b and 6-b) were exposed to the RF simulator for 1 and $2 \mathrm{~h}$ /day, respectively, for 8 days. Both Groups 5-b and 6-b were incubated with Au-NPs during the exposition. For the $7^{\text {th }}$ group, no radiation was applied and the cells were incubated with Ag-NPs for $2 \mathrm{~h}$. The $8^{\text {th }}$ and $9^{\text {th }}$ groups (Groups 8-b and 9-b) were exposed to the RF simulator for 1 and $2 \mathrm{~h} /$ day, respectively, for 8 days. Both 8-b and 9-b groups were incubated with Ag-NPs during the 
exposure time. Table 1 shows the studied groups and design of the experiment.

To investigate the radiation effects on the cells' survival, (3-[4,5-dimethylthiazol-2-yl]-2,5-iphenyltetrazolium bromide) (MTT) assay was performed on different days during and postirradiation period. Since the cell lines were adhesive, their media could simply be renewed without making any damage to the cells.

To avoid the variability inherent to the assay used, all tests were performed for three independent experiments.

\section{Statistical analysis}

A population average method, generalized estimating equation (GEE) model, was applied to consider the natural correlation of repeated measurements over the time. "There are two steps in GEE models including covariance analysis of repeated measurements over the time (across the cases) and definition of a link function between the linear predictors and the mean response. The most important feature of GEE models is the population average interpretation of the results where according to multiple cases in the data, the trend over the time is an average of multiple trends." ${ }^{222]}$ Using this method, one can evaluate the effect of different factors and covariates on the response variable. One can replace the covariate or factor by its actual measure and multiply it to the estimated coefficient, which results in a predicted value of the response. In this work for the studied groups, the synergic effects were evaluated using GEE as one unit increase in time. The results are presented as estimate of covariate/factor coefficient in the model, its standard error, and the $P$ value. Statistical analysis was performed using SPSS software version 16.0 (Chicago, IL, USA) and R.3.1.0 software (Vienna, Austria) (an open source programing environment for data analysis). For the analysis, one-way analysis of variance and multiple comparisons were applied. A significant level of 0.05 was considered for the tests.

\begin{tabular}{|c|c|c|c|c|c|c|}
\hline \multirow[t]{2}{*}{ Group } & \multicolumn{2}{|c|}{ Cell } & \multicolumn{2}{|c|}{ Irradiation } & \multicolumn{2}{|c|}{ Nanoparticle } \\
\hline & HNK & HEK & $1 \mathrm{~h} /$ day & 2 h/day & Au-NPs & Ag-NPs \\
\hline 1-a & $\checkmark$ & - & - & - & - & - \\
\hline 2-a & $\checkmark$ & - & $\checkmark$ & - & - & - \\
\hline 3-a & $\checkmark$ & - & - & $\checkmark$ & - & - \\
\hline $1-b$ & & $\checkmark$ & - & - & - & - \\
\hline $2-b$ & & $\checkmark$ & $\checkmark$ & - & - & - \\
\hline 3-b & & $\checkmark$ & - & $\checkmark$ & - & - \\
\hline 4-b & & $\checkmark$ & - & - & $\checkmark$ & - \\
\hline $5-b$ & & $\checkmark$ & $\checkmark$ & - & $\checkmark$ & - \\
\hline $6-b$ & & $\checkmark$ & - & $\checkmark$ & $\checkmark$ & - \\
\hline $7-b$ & & $\checkmark$ & - & - & - & $\checkmark$ \\
\hline 8-b & & $\checkmark$ & $\checkmark$ & - & - & $\checkmark$ \\
\hline $9-b$ & & $\checkmark$ & - & $\checkmark$ & - & $\checkmark$ \\
\hline
\end{tabular}

HNK: Human normal kidney, HEK: Human embryonic kidney, Au-NPs: Gold nanoparticles, Ag-NPs: Silver nanoparticles

\section{RESULTS AND DISCUSSION}

The size and concentrations of gold nanoparticles and silver nanoparticles

A size histogram curve of the gold-NPs, by counting at least 300 particles, showed that $45.5 \%$ of the Au-NPs were in the $20-30 \mathrm{~nm}$ range. In addition, it was found that the best concentration for the used Au-NPs was $50 \mu \mathrm{M}$. The size histogram curve of the Ag-NPs showed that $50 \%$ of the NPs were in the $25-40 \mathrm{~nm}$ range. For the used $\mathrm{Ag}-\mathrm{NPs}$, the best concentration was found to be $40 \mu \mathrm{M}$.

\section{3-(4,5-dimethylthiazol-2-yl)-2,5-iphenyltetrazolium bromide assay results}

Figure 1 shows the results of the MTT assay of HNK and HEK cells in the absence and presence of Au-NPs and Ag-NPs and also the irradiation. As stated earlier, for the control group (A), no radiation was applied, and groups $\mathrm{B}$ and $\mathrm{C}$ were irradiated to the RF simulator for 1 and $2 \mathrm{~h} /$ day, respectively. The comparison of curves in each figure shows the proliferation and variation rates of HNK and HEK cells in each step and also illustrates the effects of $\mathrm{Au}$ - and $\mathrm{Ag}$-NPs on HEK cells in the absence of irradiation.

Figure 2 shows the rate of differences of proliferation for each cell line. The effects of control, 1 and 2 times irradiation/day on each cell line can be found in these figures. Figure $2 \mathrm{a}$ and $\mathrm{b}$ show the mean optical density (OD) of HNK and HEK cells in various days for the control, 1 and 2 irradiation/day groups. In Figure $2 \mathrm{c}$ and $\mathrm{d}$, the effects of 1 and 2 irradiation/day on HEK cells in the presence of $\mathrm{Au}$ - and Ag-NPs are shown.

The mean \pm standard deviation of fraction along with time in different radiation time and groups is shown in Table 2.

The effects of all the affective parameters on the cells such as the irradiation, time, and NPs are analyzed using GEE model. The results of GEE analysis are shown in Table 3. This table includes the estimated coefficient, its standard deviation, and the $P$ value.

The table can be summarized in four different formulas for each of the groups where a significant difference was found between HNK and HEK groups. The HEK + AuNPs and $\mathrm{HEK}+\mathrm{Ag}-\mathrm{NPs}$ were statistically the same as HEK.

The four formulas for HEK, HNK, HEK + AuNPs, and $\mathrm{HEK}+\mathrm{Ag}-\mathrm{NPs}$ are as follows, respectively:

HEK as reference:

$\mathrm{OD}=0.022 \times$ day $-0.022 \times$ radiation $+0.022 \times$ day $\times$ radiation

HNK:

$\mathrm{OD}=-0.098+0.005 \times$ day $+0.024 \times$ radiation $0.009 \times$ day $\times$ radiation 


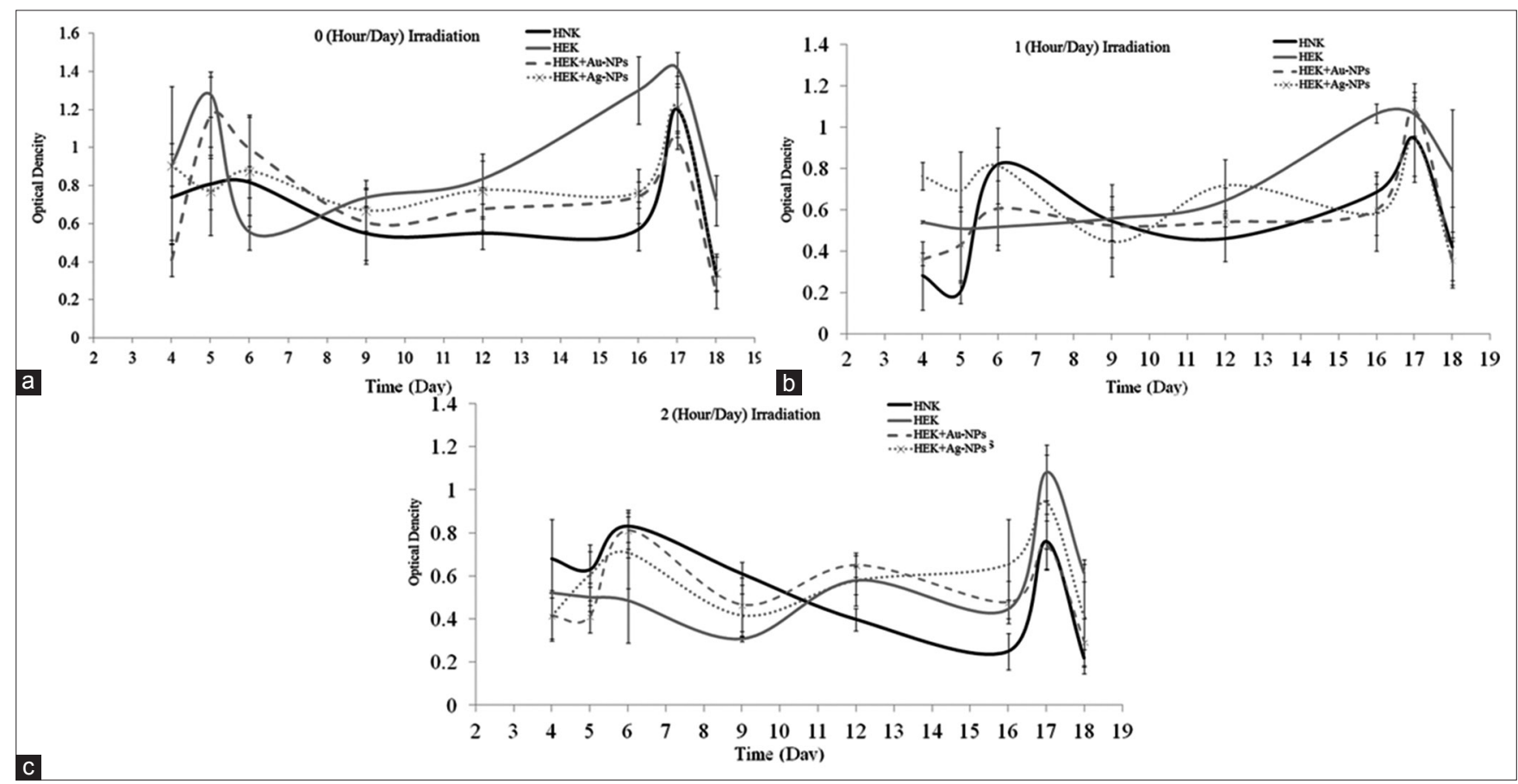

Figure 1: The optical density of cells after 3-(4,5-dimethylthiazol-2-yl)-2,5-iphenyltetrazolium bromide assay in different days for control (a), 1 (b) and 2 (c) h irradiation/day for kidney cells (groups 1-a, 2-a, and 3-a), human embryonic kidney cells (groups 1-b, 2-b, and 3-b), and human embryonic kidney cells in the presence of gold nanoparticles (groups 4-b, 5-b, and 6-b) and silver nanoparticles (groups 7-b, 8-b, and 9-b). Error bars indicate the standard deviation of the mean optical density of cells in wells in each group)

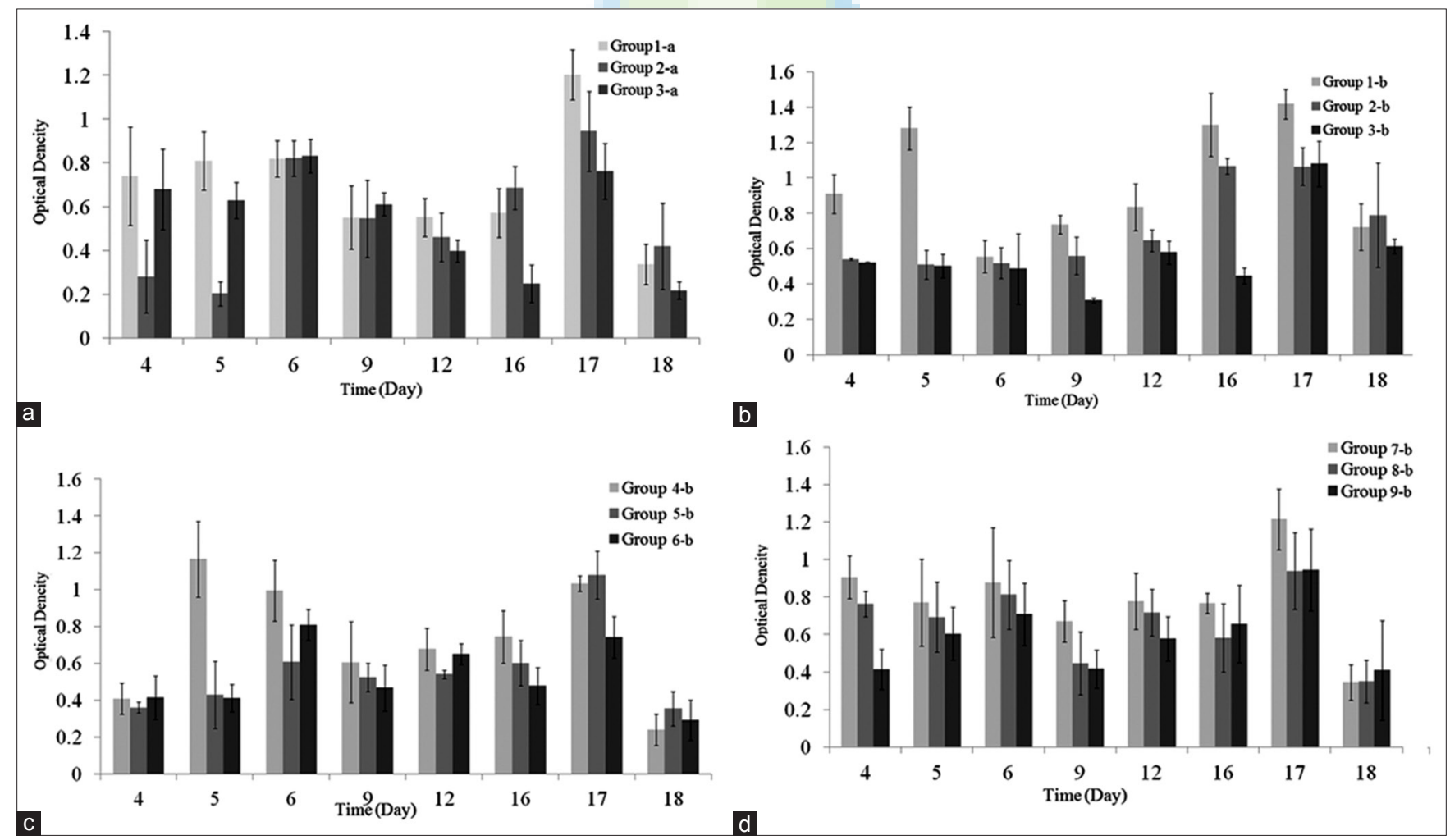

Figure 2: Optical density of cells derived from the 3-(4,5-dimethylthiazol-2-yl)-2,5-iphenyltetrazolium bromide assay for human normal kidney and human embryonic kidney cells among different exposed group (Subgroups 1-a, 2-a and 3-a [a], 1-b, 2-b and 3-b [b], 4-b, 5-b and 6-b [c] and 7-b, 8-b and 9-b [d]). Error bars indicate the standard deviation of the optical density of cells in wells for each group. 


\begin{tabular}{|c|c|c|c|c|c|c|c|c|c|c|}
\hline \multirow[t]{2}{*}{ Cell } & \multirow[t]{2}{*}{ Group } & \multirow{2}{*}{$\begin{array}{l}\text { Radiation } \\
\text { (h/day) }\end{array}$} & \multicolumn{8}{|c|}{ Time (day) } \\
\hline & & & 4 & 5 & 6 & 9 & 12 & 16 & 17 & 18 \\
\hline \multirow[t]{3}{*}{ HNK } & $1-a$ & 0 & $0.74 \pm 0.225$ & $0.81 \pm 0.133$ & $0.81 \pm 0.081$ & $0.55 \pm 0.143$ & $0.55 \pm 0.086$ & $0.57 \pm 0.111$ & $1.21 \pm 0.114$ & $0.33 \pm 0.091$ \\
\hline & $2-a$ & 1 & $0.28 \pm 0.165$ & $0.21 \pm 0.055$ & $0.82 \pm 0.081$ & $0.54 \pm 0.173$ & $0.46 \pm 0.111$ & $0.68 \pm 0.098$ & $0.94 \pm 0.182$ & $0.42 \pm 0.195$ \\
\hline & 3-a & 2 & $0.68 \pm 0.183$ & $0.63 \pm 0.082$ & $0.83 \pm 0.075$ & $0.61 \pm 0.052$ & $0.39 \pm 0.051$ & $0.24 \pm 0.084$ & $0.76 \pm 0.127$ & $0.21 \pm 0.039$ \\
\hline \multirow[t]{3}{*}{ HEK } & $1-b$ & 0 & $0.91 \pm 0.110$ & $1.28 \pm 0.119$ & $0.55 \pm 0.091$ & $0.73 \pm 0.051$ & $0.83 \pm 0.131$ & $1.31 \pm 0.177$ & $1.42 \pm 0.082$ & $0.72 \pm 0.131$ \\
\hline & $2-b$ & 1 & $0.54 \pm 0.103$ & $0.51 \pm 0.042$ & $0.52 \pm 0.049$ & $0.55 \pm 0.068$ & $0.64 \pm 0.041$ & $1.06 \pm 0.118$ & $1.06 \pm 0.098$ & $0.78 \pm 0.143$ \\
\hline & $3-b$ & 2 & $0.52 \pm 0.015$ & $0.50 \pm 0.048$ & $0.48 \pm 0.117$ & $0.31 \pm 0.013$ & $0.57 \pm 0.048$ & $0.44 \pm 0.061$ & $1.07 \pm 1.094$ & $0.61 \pm 0.035$ \\
\hline HEK + & $4-b$ & 0 & $0.41 \pm 0.084$ & $1.16 \pm 0.205$ & $0.99 \pm 0.165$ & $0.61 \pm 0.219$ & $0.67 \pm 0.113$ & $0.74 \pm 0.141$ & $1.03 \pm 0.042$ & $0.23 \pm 0.083$ \\
\hline \multirow[t]{2}{*}{ Au-NPs } & $5-b$ & 1 & $0.36 \pm 0.031$ & $0.43 \pm 0.182$ & $0.61 \pm 0.202$ & $0.52 \pm 0.076$ & $0.54 \pm 0.022$ & $0.61 \pm 0.123$ & $1.08 \pm 0.129$ & $0.35 \pm 0.094$ \\
\hline & $6-b$ & 2 & $0.41 \pm 0.117$ & $0.41 \pm 0.074$ & $0.81 \pm 0.084$ & $0.46 \pm 0.126$ & $0.64 \pm 0.055$ & $0.47 \pm 0.099$ & $0.74 \pm 0.113$ & $0.29 \pm 0.109$ \\
\hline HEK + & $7-b$ & 0 & $0.91 \pm 0.414$ & $0.77 \pm 0.231$ & $0.87 \pm 0.292$ & $0.67 \pm 0.111$ & $0.77 \pm 0.151$ & $0.76 \pm 0.052$ & $1.21 \pm 0.161$ & $0.34 \pm 0.094$ \\
\hline \multirow[t]{2}{*}{ Ag-NPs } & $8-b$ & 1 & $0.76 \pm 0.066$ & $0.69 \pm 0.186$ & $0.81 \pm 0.183$ & $0.44 \pm 0.167$ & $0.72 \pm 0.123$ & $0.58 \pm 0.181$ & $0.94 \pm 0.201$ & $0.35 \pm 0.116$ \\
\hline & $9-b$ & 2 & $0.41 \pm 0.107$ & $0.60 \pm 0.108$ & $0.71 \pm 0.131$ & $0.41 \pm 0.096$ & $0.57 \pm 0.094$ & $0.65 \pm 0.177$ & $0.94 \pm 0.241$ & $0.41 \pm 0.241$ \\
\hline
\end{tabular}

HNK: Human normal kidney, HEK: Human embryonic kidney, Au-NPs: Gold nanoparticles, Ag-NPs: Silver nanoparticles

\begin{tabular}{lccc}
$\begin{array}{l}\text { Table 3: The results of generalized estimating } \\
\text { equation analysis }\end{array}$ & \multicolumn{3}{l}{} \\
\hline Parameter & B & SE & Significant \\
\hline Day & 0.022 & 0.003 & 0 \\
Radiation & -0.222 & 0.028 & 0 \\
HEK+GNPs & 0.055 & 0.0731 & 0.45 \\
HEK+SNPs & 0.184 & 0.0626 & 0.003 \\
HNK & -0.098 & 0.0968 & 0.309 \\
HEK & Reference & & \\
Day $\times$ radiation & 0.002 & 0.002 & 0.338 \\
(HEK + GNPs) $\times$ day & -0.027 & 0.0053 & 0 \\
(HEK + SNPs) $\times$ day & -0.032 & 0.0044 & 0 \\
(HNK) $\times$ day & -0.017 & 0.0068 & 0.015 \\
(HEK) $\times$ day & Reference & & \\
(HEK + GNPs) $\times$ radiation & 0.055 & 0.0482 & 0.253 \\
(HEK + SNPs) $\times$ radiation & 0.033 & 0.0412 & 0.418 \\
(HNK) $\times$ radiation & 0.246 & 0.0625 & 0 \\
(HEK) $\times$ radiation & Reference & & \\
(HEK + GNPs) $\times$ day $\times$ radiation & 0.004 & 0.0035 & 0.235 \\
(HEK + SNPs) $\times$ day $\times$ radiation & 0.006 & 0.0036 & 0.08 \\
(HNK) $\times$ day $\times$ radiation & -0.011 & 0.0045 & 0.015 \\
(HEK) $\times$ day $\times$ radiation & Reference & & \\
\hline
\end{tabular}

The table includes the estimated coefficient, its SE, and the P value. SE: Standard of error, HNK: Human normal kidney, HEK: Human embryonic kidney, SNPs: Silver Nano Particles, GNPs: Gold Nano Particles, SD: Standard deviation

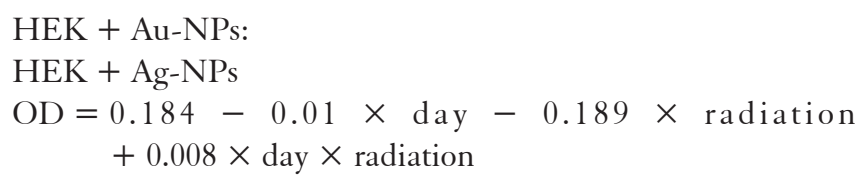

To find the GEE rates using the formulas for different groups, the baseline could be found by eliminating day from the formulas and one can replace the day by its exact measure (e.g., 2 for day 2) for any desired day. Moreover, nonradiation condition can be performed to the formulas by eliminating the radiation from them and one can replace it by any desired radiating time, the same as day.

According to the model, as day and radiation time increase, the OD decreases in HNK group with a significant difference to the HEK $(P=0.015)$. Moreover, the increase in HEK + Ag-NPs and HEK + Au-NPs is statistically the same as for the HEK group $(P>0.05)$.
At the baseline with no radiation, a significant difference was found between the HEK and HEK $+\mathrm{Ag}$-NPs groups $(P=0.015)$ and along with the time, the groups of HNK, HEK + Ag-NPs, and HEK + Au-NPs were statistically developing in different shapes $(P<0.001)$. In other words, the mean OD in HNK, $\mathrm{HEK}+\mathrm{Ag}-\mathrm{NPs}$, and HEK + Au-NPs was 0.098 less, 0.184 and 0.055 more than HEK, respectively, where these differences were significant only by comparing HEK to the HEK + Ag-NPs groups. Along with the time, the mean OD in HNK, $\mathrm{HEK}+\mathrm{Ag}-\mathrm{NPs}$, and HEK + Au-NPs groups in comparison to the HEK increased by the rate of 0.005 and decreased by the rates of 0.01 and 0.005 , respectively.

At the baseline and along with the time with irradiating the groups for $1 \mathrm{~h}$, a significant difference in mean fraction was found between the HNK and HEK groups. The mean fraction in HNK, HEK + Ag-NPs, and HEK + Au-NPs was 0.074, 0.005, and 0.112 less than HEK at the baseline, while longitudinally comparing to the HEK group, the mean fraction decreased by the rates of $0.004,0.002$, and 0.001 , respectively.

Considering the irradiated groups for $2 \mathrm{~h}$, a significant difference in the proliferation of the HNK and HEK compared to the baseline as well as along with the days was found. The fraction mean at the baseline in HNK, HEK + Ag-NPs, and $\mathrm{HEK}+\mathrm{Au}-\mathrm{NPs}$ groups was 0.046,0.19, and 0.275 less compared to the HEK. Along with 1 day passing the time, the mean OD in HNK, HEK + Ag-NPs, and HEK + Au-NPs decrease by 0.017 and increase by 0.002 and 0.003 , respectively.

The effects of RF on human health are not completely understood, and there is some controversy about them. ${ }^{[1-4]}$ One idea is that their biological outcomes are due to their thermal effects. ${ }^{[5]}$ Blank and Goodman assumed that the mechanism of EM signal transduction in the cell membrane may be explained by direct interaction of electric and magnetic fields with mobile charges within enzymes. ${ }^{[23]}$ Cellular response to EM fields is activation of the same stress response system seen in heating, but at very much lower energy than the response to heat shock. ${ }^{[23]}$ In this study, we have investigated the effect of RFR on the proliferation 
and survival fraction of two cells of HNK and HEK. According to statistical analysis for the HNK cells, the mean cell death in three groups of radiation (1-a, 2-a, and 3-a) is the same and does not show significant differences $(P>0.05)$. Although the average cell death in various days is different, these differences are similar. Therefore, it can be concluded that the RFR exposed to 1 and $2 \mathrm{~h}$ /day for 8 days did not affect the HNK cells.

For HEK cells, the average cell death in various days and exposed groups (1-b, 2-b, and 3-b) was significantly different. The results of statistical analysis showed that the mean cell death in group 3-b was significantly higher $(P<0.05)$ compared to groups $1-\mathrm{b}$ and 2-b. It can be understood that RF can damage the HEK cells' exposition which is performed for $2 \mathrm{~h} /$ day for 8 days. Therefore, there are different results for these two cells. Investigating the previous studies shows that some researchers such as Phillips et al. reported DNA single-strand breaks exposed to cellular telephone frequencies; also, they proposed that DNA repair rates may be affected by exposure to RF. ${ }^{[24]}$ Lai and Singh reported DNA strand breaks from RF at low-intensity levels. In addition, they reported a dose-dependent increase in DNA single- and double-strand breaks in brain cells after $2 \mathrm{~h}$ of exposure to $2450 \mathrm{MHz}$ RFR. ${ }^{[25]}$ Hence, large parts of the DNA damages can redound to cell death; it can be concluded that the cell death or repair after exposure is due to the ability to repair after damage. As the rate of cell proliferation in HNK cells is lower than the HEK cells, it can be concluded that for the high-rate proliferation cells, RFR can affect the cells and their death rate. Some studies indicated that the cells' growth rate represented a curve with an exponential reduction in clonogenic survival as a function of time at the temperature range of $43^{\circ} \mathrm{C}-47^{\circ} \mathrm{C} \cdot{ }^{[26,27]}$ These results are in a good agreement with our findings.

As the tumor cells have a more rapid proliferation cycle than the normal healthy cell, the RF ablation method results in successful partial necrosis of tumor, but turns out to be dangerous in many situations as the improvement of blood circulation under RFR can provoke a further development of tumors, and it is applicable only for a few organ sites (liver, kidney, breast, lung, and bone). ${ }^{[28,29]}$

Hence, if the thermal energy of RF could be localized in malignant tissue deep within the body without damaging the surrounding healthy tissues, it could be used to increase the tumor cells' death. ${ }^{[14]}$ One proposed method is the use of some metallic or semiconducting NPs which heat in an electromagnetic field and can significantly enhance the cells' temperature. ${ }^{[30,31]}$

To investigate the effects of MNPs in increasing the effects of $\mathrm{RF}$ radiations, two NPs of Au-NPs and Ag-NPs were used. The effects of 1 and $2 \mathrm{~h} /$ day $\mathrm{RF}$ radiation were investigated in the presence of these NPs.

Absorption of infrared light induces surface plasmon resonance that is converted to heat. ${ }^{[32]}$ Therefore, Au-NPs can be used widely in hyperthermia procedures. The Ag-NPs have the same properties as mentioned for Au-NPs, and it was predicted that these NPs can be useful in increasing the hyperthermia effects of RF. Resonant absorption peak and cross section of nanostructures can vary based on their size and shape. ${ }^{[33-35]}$

The results of using RF radiations when the HEK cells are in proximity of $\mathrm{Au}-\mathrm{NPs}$ showed that the differences between groups 4-b, 5-b, and 6-b are statistically significant $(P<0.05)$. The cell death in group 6-b was higher than 5-b and both of them were significantly higher than 4-b. Therefore, the use of Au-NPs can increase the effect of $\mathrm{RF}$ radiation on HEK cells.

However, the results of the use of Ag-NPs did not show significant effects as the Au-NPs. Although the average cell death in groups 7-b, 8-b, and 9-b was different, this difference was not statistically significant $(P>0.05)$. Therefore, it can be concluded that, in term of this work, the Ag-NPs do not increase the effect of RF radiations as same as the Au-NPs.

\section{CONCLUSIONS}

RF radiation can affect both HNK and HEK cells when irradiated for $2 \mathrm{~h} /$ day for 8 days. The results showed that the Ag-NPs do not increase the synergetic effects of RF compared to the Au-NPs. RF radiation in the presence of Au-NPs can be used as an efficient treatment for melanoma cancer.

Financial support and sponsorship

Nil.

\section{Conflicts of interest}

There are no conflicts of interest.

\section{REFERENCES}

1. Penafiel LM, Litovitz T, Krause D, Desta A, Mullins JM. Role of modulation on the effect of microwaves on ornithine decarboxylase activity in L929 cells. Bioelectromagnetics 1997;18:132-41.

2. Fattahi-AsI J, Karbalaei M, Nasri P. Non-ionizing radiation and human serum. J Radiobiol 2014;1:28-30.

3. Zeni O, Romanò $M$, Perrotta A, Lioi MB, Barbieri R, d'Ambrosio G, et al. Evaluation of genotoxic effects in human peripheral blood leukocytes following an acute in vitro exposure to $900 \mathrm{MHz}$ radio frequency fields. Bioelectromagnetics 2005;26:258-65.

4. Shahbazi-Gahrouei D, Mortazavi SM, Nasri H, Baradaran A, Baradaran-Ghahfarokhi M, Baradaran-Ghahfarokhi HR. Mobile phone radiation interferes laboratory immunoenzymometric assays: Example chorionic gonadotropin assays. Pathophysiology 2012;19:43-7.

5. Nikfarjam M, Muralidharan V, Christophi C. Mechanisms of focal heat destruction of liver tumors. J Surg Res 2005;127:208-23.

6. Lepock JR. Cellular effects of hyperthermia: Relevance to the minimum dose for thermal damage. Int $\mathrm{J}$ Hyperthermia 2003;19:252-66.

7. Miles CA. Relating cell killing to inactivation of critical components. Appl Environ Microbiol 2006;72:914-7. 
8. Gómez-Millán J, Katz IS, Farias Vde A, Linares-Fernández JL, López-Peñalver J, Ortiz-Ferrón G, et al. The importance of bystander effects in radiation therapy in melanoma skin-cancer cells and umbilical-cord stromal stem cells. Radiother Oncol 2012;102:450-8.

9. Dickson JA, Calderwood SK. Temperature range and selective sensitivity of tumors to hyperthermia: A critical review. Ann N Y Acad Sci 1980;335:180-205.

10. Overgaard K, Overgaard J. Investigations on the possibility of a thermic tumour therapy. I. Short-wave treatment of a transplanted isologous mouse mammary carcinoma. Eur J Cancer 1972;8:65-78.

11. Mirza AN, Fornage BD, Sneige N, Kuerer HM, Newman LA, Ames FC, et al. Radiofrequency ablation of solid tumors. Cancer J 2001;7:95-102.

12. Wu $\mathrm{Y}$, Tang $\mathrm{Z}$, Fang $\mathrm{H}$, Gao $\mathrm{S}$, Chen J, Wang $\mathrm{Y}$, et al. High operative risk of cool-tip radiofrequency ablation for unresectable pancreatic head cancer. J Surg Oncol 2006;94:392-5.

13. Gannon CJ, Curley SA. The role of focal liver ablation in the treatment of unresectable primary and secondary malignant liver tumors. Semin Radiat Oncol 2005;15:265-72.

14. Fenn AJ, Sathiaseelan V, King GA, Stauffer PR. Improved localization of energy deposition in adaptive phased-array hyperthermia treatment of cancer. Linc Lab J 1996;9:187-96.

15. Raoof M, Corr SJ, Zhu C, Cisneros BT, Kaluarachchi WD, Phounsavath $\mathrm{S}$, et al. Gold nanoparticles and radiofrequency in experimental models for hepatocellular carcinoma. Nanomedicine 2014;10:1121-30.

16. Hanson GW, Patch SK. Optimum electromagnetic heating of nanoparticle thermal contrast agents at if frequencies. J Appl Phys 2009;106:1141-9.

17. Glazer ES, Zhu C, Massey KL, Thompson CS, Kaluarachchi WD, Hamir AN, et al. Noninvasive radiofrequency field destruction of pancreatic adenocarcinoma xenografts treated with targeted gold nanoparticles. Clin Cancer Res 2010;16:5712-21.

18. Gannon CJ, Cherukuri P, Yakobson BI, Cognet L, Kanzius JS, Kittrell C, et al. Carbon nanotube-enhanced thermal destruction of cancer cells in a noninvasive radiofrequency field. Cancer 2007;110:2654-65.

19. Moran $\mathrm{CH}$, Wainedi SM, Cherukuri TK, Kittrell C, Wiley BJ, Nicholas NW, et al. Size-dependent joule heating of gold nanoparticles using capacitively coupled radiofrequency fields. Nano Res 2009;2:400-5.

20. Asín L, Ibarra MR, Tres A, Goya GF. Controlled cell death by magnetic hyperthermia: Effects of exposure time, field amplitude, and nanoparticle concentration. Pharm Res 2012;29:1319-27.

21. Bhattacharya R, Mukherjee $P$, Xiong Z, Atala A, Soker S,
Mukhopadhyay D. Gold nanoparticles inhibit VEGF165-induced proliferation of HUVEC cells. Nano Lett 2004;4:2479-81.

22. Nikzad S, Hashemi B, Hasan ZS, Mozdarani $H$, Baradaran-Ghahfarokhi M, Amini P. The application of the linear quadratic model to compensate the effects of prolonged fraction delivery time on a Balb/C breast adenocarcinoma tumor: An in vivo study. Int J Radiat Biol 2016;92:80-6.

23. Blank M, Goodman R. Do electromagnetic fields interact directly with DNA? Bioelectromagnetics 1997;18:111-5.

24. Phillips J, Ivaschuk O, Ishida-Jones T, Jones RA. DNA damage in Molt-4 T-lymphoblastoid cells exposed to cellular telephone radiofrequency fields in vitro. Bioelectrochem Bioenerg 1998;45:103-10.

25. Lai $H$, Singh NP. Acute low-intensity microwave exposure increases DNA single-strand breaks in rat brain cells. Bioelectromagnetics 1995;16:207-10.

26. Raaphorst GP, Freeman ML, Dewey WC. Radiosensitivity and recovery from radiation damage in cultured $\mathrm{CHO}$ cells exposed to hyperthermia at $\mathbf{4 2 . 5}$ or $\mathbf{4 5 . 5}$ degrees C. Radiat Res 1979;79:390-402.

27. Dewey WC, Hopwood LE, Sapareto SA, Gerweck LE. Cellular responses to combinations of hyperthermia and radiation. Radiology 1977;123:463-74.

28. Panagopoulos DJ, Karabarbounis A, Margaritis LH. Mechanism for action of electromagnetic fields on cells. Biochem Biophys Res Commun 2002;298:95-102.

29. Gazelle GS, Goldberg SN, Solbiati L, Livraghi T. Tumor ablation with radio-frequency energy. Radiology 2000;217:633-46.

30. Ichinoseki-Sekine N, Naito H, Saga N, Ogura Y, Shiraishi M, Giombini A, et al. Effects of Microwave Hyperthermia at Two Different Frequencies (434 and $2450 \mathrm{MHz}$ ) on Human Muscle Temperature. J Sports Sci Med 2008;7:191-3.

31. Curley SA, Palalon F, Sanders KE, Koshkina NV. The effects of non-invasive radiofrequency treatment and hyperthermia on malignant and nonmalignant cells. Int $\mathrm{J}$ Environ Res Public Health 2014;11:9142-53.

32. Verma J, Lal S, Van Noorden CJ. Nanoparticles for hyperthermic therapy: Synthesis strategies and applications in glioblastoma. Int J Nanomedicine 2014;9:2863-77.

33. Shahbazi-Gahrouei D, Razavi S, Salimi M. Effect of extremely low-frequency $(50 \mathrm{~Hz})$ field on proliferation rate of human adipose-derived mesenchymal stem cells. J Radiobiol 2014;1:31-7.

34. Narang RS, Narang JK. Nanomedicines for dental applications-scope and future perspective. Int J Pharm Investig 2015;5:121-3.

35. Ali J. Nanopharmaceutics. Int J Pharm Investig 2011;1:61. 